Please do not remove this page

RMIT

UNIVERSITY

\title{
Novel drug carriers: From grafted polymers to cross-linked vesicles
}

Xu, Jiangtao; Fu, Qiang; Ren, Jing; Bryant, Gary; Qiao, Greg

https://researchrepository.rmit.edu.au/esploro/outputs/9921859481701341/filesAndLinks?institution=61RMIT_INST\&index=null

Xu, J., Fu, Q., Ren, J., Bryant, G., \& Qiao, G. (2013). Novel drug carriers: From grafted polymers to cross-linked vesicles. Chemical Communications, 49(1), 33-35. https://doi.org/10.1039/c2cc37319j

Document Version: Accepted Manuscript

Published Version: https://doi.org/10.1039/c2cc37319j

Repository homepage: https://researchrepository.rmit.edu.au

(c) 2012 The Royal Society of Chemistry

Downloaded On 2023/04/26 19:55:39 +1000

Please do not remove this page 
Thank you for downloading this document from the RMIT Research Repository.

The RMIT Research Repository is an open access database showcasing the research outputs of RMIT University researchers.

RMIT Research Repository: http://researchbank.rmit.edu.au/

\section{Citation:}

Xu, J, Fu, Q, Ren, J, Bryant, G and Qiao, G 2013, 'Novel drug carriers: From grafted polymers to cross-linked vesicles', Chemical Communications, vol. 49, no. 1, pp. 33-35.

See this record in the RMIT Research Repository at:

http://researchbank.rmit.edu.au/view/rmit:18150

Version: Accepted Manuscript

Copyright Statement: (c) 2012 The Royal Society of Chemistry

Link to Published Version:

http://dx.doi.org/10.1039/c2cc37319j 


\title{
Novel Drug Carriers: From Grafted Polymers to Cross-linked Vesicles $\uparrow$
}

\author{
Jiangtao Xu, ${ }^{a}$ Qiang Fu, ${ }^{a}$ Jing M. Ren, ${ }^{a}$ Gary Bryant ${ }^{b}$ and Greg G. Qiao* ${ }^{a}$
}

\begin{abstract}
A simple and straightforward method of self-assembling grafted copolymers was developed to fabricate cross-linked polymer vesicles, which could conjugate anticancer drug cis-platinum and possess the capability of a high drug loading content, and a steady release rate.
\end{abstract}

Synthetic polymer nanoparticles have long been sought as nano-carriers for drug delivery because they are amenable to precise morphological control and surface modification. ${ }^{1}$ Polymer vesicles are particularly attractive materials since their sizes, structures and functions can be readily tailored to suit many desirable applications in nanomedicine through careful selection of the polymer structures and properties. $^{2}$

Of particular interest is the preparation of polymer vesicles in aqueous solution from different topological copolymers. The intrinsic macromolecular parameters including block copolymer architecture, hydrophobic interactions, and the hydrophobic/hydrophilic balance, determine the nature of the morphologies of these block copolymers. Among them, block copolymer architecture has been extensively investigated for simple linear-linear (coil-coil, coil-rod, rod-rod, and supplementary interaction), ${ }^{3}$ and linear-branched (or dendrimer) structures. ${ }^{4}$

Herein, we report on the construction of robust polymer vesicles self-assembled from linear-brush polyoxanorbornene-based diblock copolymers by $\mathrm{pH}$ triggering. The double bonds formed in the polymer backbone provide the capability of cross-linking vesicular structure by thiol-ene "click" chemistry with a biodegradable linker. These cross-linked polymer vesicles can be utilized to conjugate anticancer drug cis-platinum with high loading content. To the best of our knowledge, this is the first example of a morphological investigation of grafted copolymers self-assembled in aqueous condition.

We designed linear-brush diblock copolymers, 3 in Scheme 1, via ring-opening metathesis polymerization (ROMP) utilizing two monomers, oxanorbornenyl anhydride (ONBAn) and $\omega$ oxanorbornenyl poly(ethylene glycol) $\left(M_{\mathrm{n}}=2000\right)$ macromonomer (ONB-PEG2K, 2, ESI). The anhydrides in the linear block would be modified to di-acid functionalities through hydrolysis, which would be responsive towards $\mathrm{pH}$ in aqueous solution and also provide binding sites for cis-platinum drug conjugation. The oxygen in the oxanorbornene monomer was expected to be more hydrophilic and hence increase the probability of biocompatibility for the resulting copolymers. ${ }^{5}$ PEG was employed to construct the brush block due to its prestige as the most important and widely used biocompatible polymer in pharmaceutical and biomedical applications. Brush and hyperbranched polymers generally display longer in vivo retention times compared to their linear polymer analogues. ${ }^{6}$

ROMP initiated by ruthenium Grubbs' catalyst is a powerful tool to make well-defined polymers with low polydispersity, high conversion, and precisely controlled degrees of polymerization by easily adjusting the monomer to catalyst ratio. Particularly, it has been proved to be very useful to make brush polymers. ${ }^{7}$ The linear-brush block copolymers, $\mathrm{P}(\mathrm{ONBAn})_{\mathrm{m}}-b-\mathrm{P}(\mathrm{ONB}-\mathrm{PEG} 2 \mathrm{~K})_{\mathrm{n}}$, with two different block ratios were synthesized via sequential addition of (macro)monomers of ONBAn and ONBPEG2K in the presence of pyridine modified $2^{\text {nd }}$ generation Grubbs' catalyst. It gave light grey powder, 3: $M_{\mathrm{n}}(\mathrm{GPC})=14,500, M_{\mathrm{w}} / M_{\mathrm{n}}=1.14$ for $\mathrm{P}(\mathrm{ONBAn})_{25}-b-\mathrm{P}(\mathrm{ONB}-\mathrm{PEG} 2 \mathrm{~K})_{5}$ and $M_{\mathrm{n}}(\mathrm{GPC})=19,400$, $M_{\mathrm{w}} / M_{\mathrm{n}}=1.16$ for $\mathrm{P}(\mathrm{ONBAn})_{50}-b-\mathrm{P}(\mathrm{ONB}-\mathrm{PEG} 2 \mathrm{~K})_{5}$.

Hydrolysis was carried out in $0.1 \mathrm{M} \mathrm{NaOH}$ solution for $1 \mathrm{hr}$. After dialysis against deionized water, the polymer solutions were freeze-dried to give viscous products, 4: diblock copolymers $\mathrm{P}(\mathrm{ONB}-$ diacid $)_{25}-b-\mathrm{P}(\mathrm{ONB}-\mathrm{PEG} 2 \mathrm{~K})_{5}$ (denoted as DP25) and $\mathrm{P}(\mathrm{ONB}-\mathrm{diacid})_{50}-b-\mathrm{P}(\mathrm{ONB}-\mathrm{PEG} 2 \mathrm{~K})_{5}$ (denoted as DP50).

\footnotetext{
${ }^{a}$ Department of Chemical and Biomolecular Engineering, The University of Melbourne, Parkville, VIC 3010, Australia Fax: XXXXXXXXXX; Tel: XXXXXXXXXX; E-mail: gregghq@unimelb.edu.au

${ }^{b}$ School of Applied Sciences, RMIT University, Melbourne, VIC 3000, Australia
} 
The self-assembly proceeded via dissolution of the diblock copolymer 4 at a concentration of $3 \mathrm{mg} / \mathrm{mL}$. The $\mathrm{pH}$ value of the solution was adjusted to be $\sim 12$ (measured by $\mathrm{pH}$ meter) by adding $2 \mathrm{M} \mathrm{NaOH}$ solution. Subsequently, $2 \mathrm{M} \mathrm{HCl}$ was added slowly into the solution to tune $\mathrm{pH}$ values. Dynamic light scattering (DLS) studies of these solutions with varied $\mathrm{pH}$ value (Fig. 1A and Fig. S5) for DP25 were performed. Fig. 1A showed that $D_{\mathrm{h}}$ did not change as the $\mathrm{pH}$ decreased from 12 to 5 . It was around $5 \mathrm{~nm}$, which means the polymers were dissolved molecularly. However, the size abruptly increased from $5 \mathrm{~nm}$ to $150 \mathrm{~nm}$ as $\mathrm{pH}$ decreased from 5 to 4 , which indicated the formation of micellar aggregates.

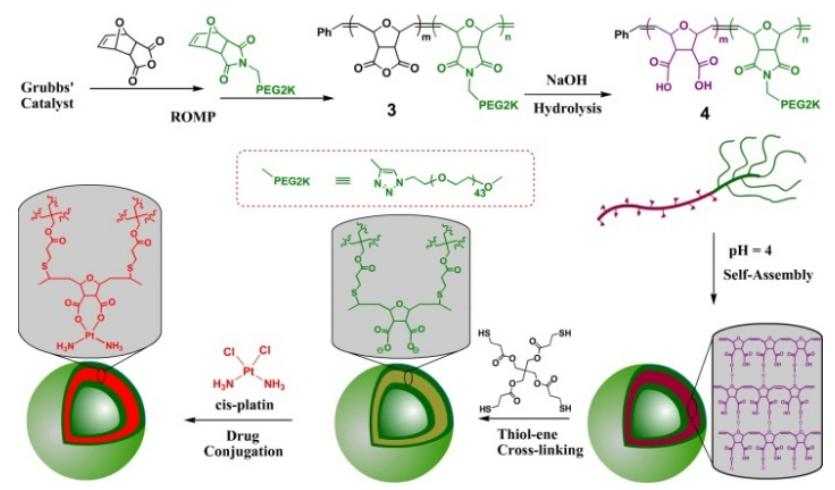

Scheme 1 The chemistry of constructing cross-linked polymer vesicles and their drug conjugation with cis-platinum.
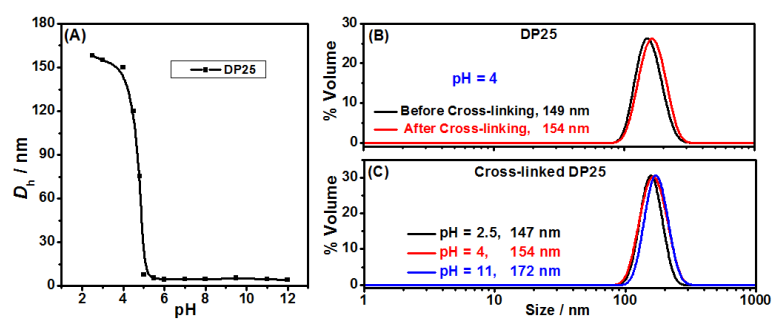

Fig. 1 Hydrodynamic particle sizes $\left(D_{\mathrm{h}}\right)$ of self-assembled DP25 (A) at varied $\mathrm{pH}$ before cross-linking, (B) at $\mathrm{pH} 4$ before and after cross-linking, and (C) at different $\mathrm{pH}$ after cross-linking.

It is well known that poly(carboxylic acid) chains undergo dramatic conformational changes, from an extended rod-like chain to a hypercoil as the $\mathrm{pH}$ value decreases. Such a change occurs gradually over a large $\mathrm{pH}$ range. Thus, the sharp transition at $\mathrm{pH} 4 \sim 5$ in Fig. 1 cannot only be attributed to the simple conformational variation of poly(carboxylic acid) chains. In fact, the acid in poly(carboxylic acid) acting as a proton-donating groups can form interpolymer complexes (IPC) by H-bonding with protonaccepting ether groups in some polymers like PEG and poly(vinyl ether) at low $\mathrm{pH}$. This phenomenon had been extensively studied since it was first reported in $1959 .{ }^{8}$ Therefore, the sharp transition at $\mathrm{pH} 4$ $\sim 5$ in our work could be attributed to IPC between poly(carboxylic acid) and polyoxanorbornene ether backbone or PEG brush (Scheme S2). However, accompanying the hydrophobic intermolecular association of poly(carboxylic acid)s, it was proposed that the complexation between poly(carboxylic acid) and polyoxanorbornene ether backbone would be more favorable than that between poly(carboxylic acid) and PEG brush.

Taking into account the semi-rigidity of the polyoxanorbornene backbones, the molecular packing and IPC will tend to form bilayer structure, i.e. vesicles, at $\mathrm{pH} 4$. Obviously, the particle size $\left(D_{\mathrm{h}}=150 \mathrm{~nm}\right)$ was far higher than the maximum theoretical value for spherical micelles $(\sim 74 \mathrm{~nm}$ for the fully extended chain length of the constituent blocks, roughly estimated by summation of the average backbone length unit of C-C-O at $0.23 \mathrm{~nm}$ ). Furthermore, light scattering (LS), transmission electron microscopy (TEM) and atomic force microscopy (AFM) measurements provided convincing evidence that the structures are vesicles. However, cross-linking of the vesicles can provide a permanent vesicle for morphology 
observed.??

Due to the olefin functionalities on polyoxanorbornene backbone, which can be applied for the thiolene click reaction ${ }^{9}$ with high tolerance in many different conditions and solvents, ${ }^{10}$ these vesicles were cross-linked by tetra-functional thiol cross-linker, pentaerythritol tetrakis(3-mercaptopropionate) (PETMP), in the presence of photo initiator, 2,2-dimethoxy-2-phenyl acetophenone (DMPA). It is worthy to note that $\beta$-thioester bonds in PETMP were used as a labile linker because it can be easily hydrolyzed by esterase, which is abundant in cells. ${ }^{11}$ Therefore, the resultant cross-linked polymer vesicles are likely to be biodegradable if used as drug carriers. Although the grafted polymer segments cannot degrade, they can be cleared from blood circulation since their molecular weights are far below renal clearance threshold ( $40 \mathrm{~K}$ for linear $\mathrm{PEG}) .^{12}$

The cross-linker and photo initiator were encapsulated into the hydrophobic part of polyacid aggregates due to their hydrophobic properties. The thiol-ene "click" reaction was performed under 365 nm UV light overnight. DLS measurements (Fig. 1B) confirmed that the particle size did not change $(\sim 150 \mathrm{~nm})$ before and after cross-linking.

DLS studies (Fig. 1C) showed the particles had expanded after cross-linking and dialysis, around 150 $\mathrm{nm}$ at $\mathrm{pH}$ lower than 4 to $18 \mathrm{~nm}$ at $\mathrm{pH} 11$. This size increase was due to increased swelling of the particles when $\mathrm{pH}$ was increased. A control experiment was performed under identical reaction condition without PETMP; upon changing of $\mathrm{pH}$ to 7, no large-sized nanoparticles were observed by DLS, which indicates the disassembly of uncross-linked polymer particles. The other grafted copolymer DP50 gave similar results in DLS (Fig. S6, ESI) with particle size of $\sim 190 \mathrm{~nm}$ at low $\mathrm{pH}$ and $\sim 210 \mathrm{~nm}$ at high $\mathrm{pH}$ after cross-linking.

The combination of DLS and SLS measurement can provide detailed information of vesicles, including vesicle size, shell thickness and size distribution. ${ }^{13}$ Theoretical analysis of SLS measurements of the cross-linked polymer vesicles was conducted using established mathematical models. ${ }^{14}$ For the cross-linked polymer vesicle from diblock copolymer $\mathrm{P}(\mathrm{ONB} \text {-diacid })_{25}-\mathrm{b}-\mathrm{P}(\mathrm{ONB}-\mathrm{PEG} 2 \mathrm{~K})_{5}$ (denoted as CPV25), the best fit was achieved using a hollow sphere (vesicle) model (Equation S1, red line in Fig. S7) with a log-normal distribution of particle sizes. This model is in reasonable agreement with the SLS data, yielding a diameter of $132 \mathrm{~nm}$, which matches well with the DLS data. Moreover, the shell thickness was calculated to be $27 \mathrm{~nm}$. By comparison, no good fit could be obtained using the solid sphere (micelle) model (Equation S3, green line in Fig S7). The other sample of cross-linked polymer vesicle from diblock copolymer $\mathrm{P}(\mathrm{ONB}-\text { diacid) })_{50}-b-\mathrm{P}(\mathrm{ONB}-\mathrm{PEG} 2 \mathrm{~K})_{5}$ (denoted as CPV50) was fitted (Fig. S8) using the vesicle model with a Schulz distribution, yielding a diameter of $188 \mathrm{~nm}$ and shell thickness of $37 \mathrm{~nm}$. Again no good fit could be obtained using a micelle model.
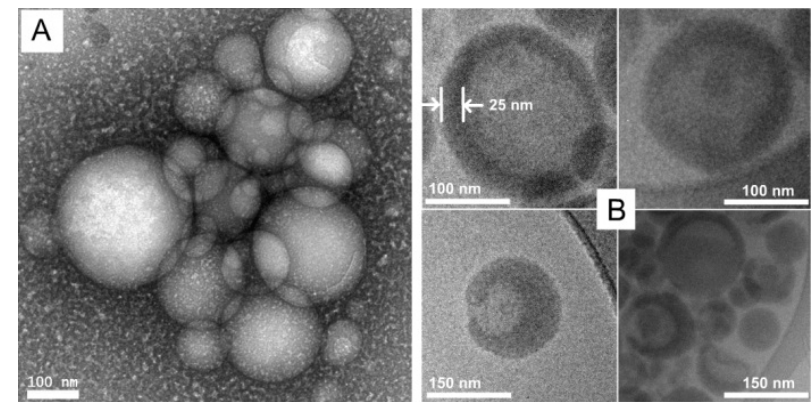

Fig. 2 TEM images with negative staining (A) and cryo-TEM images with positive staining (B) for CPV25.

Analysis of a dried sample of the CPV25 by TEM negatively stained with uranyl acetate showed polydisperse spherical micelles with average $\sim 155 \mathrm{~nm}$ particle size (Fig. 2A and Fig. S10), which agrees with LS results. The high polydispersity originates from the formation mechanism of polymer vesicles. Generally, they are formed from a block copolymer to an assembled single bilayer membrane, with a hydrophobic middle layer and hydrophilic surfaces, and the resulting membrane folds over and rearranges by connecting its edges to enclose a space. No mechanism selects for the overall size, so the size distribution tends to be very polydisperse. It also induced the morphologies of fully enclosed and 
partially enclosed vesicles, which can be seen in TEM and AFM measurements.

Upon positive staining with loaded drug cis-platinum (selective staining for the di-acid block), definable bilayer structure with $25 \mathrm{~nm}$ shell thickness were observed from cryo-TEM (Fig. 2B and Fig. S11), clearly indicating vesicular morphology. The shell thickness was a little smaller than that from LS results $(27 \mathrm{~nm})$ due to unstained thin PEG layers. Additionally, it indicated that some bowl-shaped and partially enclosed vesicles (Fig. 2B bottom and Fig. S11C, ESI) were observed.

AFM measurement (Fig. S12) further confirmed the results by a diameter to height ratio of 7.5 to 1 , a hollow property of the nanoparticles. The height showed doubled shell thickness of the polymer vesicles. With a single thickness of around $22 \mathrm{~nm}$, which is slightly smaller than $25 \mathrm{~nm}$ from cryo-TEM measurements, as the AFM sample in the dried state.

These novel cross-linked polymer vesicles are ideal nano-carriers for anti-cancer drug cis-platinum, because the diacid bilayer shell has the tendency to bind cis-platinum, forming metal complexes which can release drugs by hydrolytically cleaving carboxylic groups. Moreover, dicarboxylate-platinum complexes with a 6 8 membered ring structure can normally provide higher stability and loading contents to their conjugates. ${ }^{15}$ In this work, the di-acid structures have the potential to form stable platinum complex with 7-membered rings.

In a specific experiment, the basic solution $(\mathrm{pH}=12)$ of CPV25 was mixed with freshly prepared cisdiaminediaqua platinum(II) complex solution from cis-dichlorodiamine-platinum(II) (CDDP) at given carboxylate/cis-platinum molar ratios (2/1), resulting in light brown solution in an extremely short time ( $<5 \mathrm{~min})$. It presented the rapid formation of polymer-platinum conjugates as well as high drug conjugation efficiency determined by TGA to be $88.4 \%$ (see Fig. S13 and its calculation in ESI), which suggested that most carboxylate functional groups were involved in complex formation as 7-membered ring complexes. We believed that this stable complex promoted effective drug conjugation. However, no morphology for this complex structure can be determined without further investigation.. However, this is not a concern when good drug loading and release profiles are obtained. The drug loading content was calculated to be $18.9 \%$ based on the conjugation efficiency, which is much higher than previously reported (generally less than $10 \%{ }^{16}$ ).

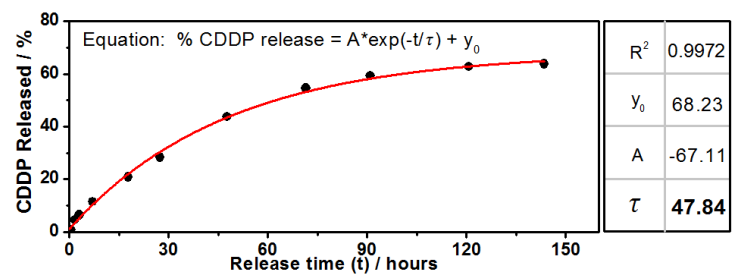

Fig. 3 Release profile of CDDP from CPV25 in saline solution $(0.9 \% \mathrm{NaCl}, \mathrm{pH} 7.4)$. The line was fitted according to equation $\% \mathrm{CDDP}$ released $=\mathrm{A} \exp (-\mathrm{t} / \tau)+\mathrm{y}_{0}$.

The in vitro release of the CDDP from a polymer vesicle solution was performed by a dialysis method. ${ }^{15}$ As shown in Fig. 3, the drug release profile followed a steady release rate, which meets the criterion that drug levels in the body remain constant while the drug is being administered. The release kinetics can be described by a simple first-order mathematical model, although the release behaviour is complicated, combining diffusion (out of polymer vesicles) and chemically controlled processes (decomplexation). ${ }^{17}$ It gave similar results to those reported by Huynh et al, ${ }^{15}$ with release constant, $\tau, 47.84$ hours.

In summary, this work presents a straightforward method to prepare biodegradable cross-linked polymer vesicles, which are capable of conjugating cis-platinum drug with a high loading content and steady release rate. The polymer vesicles were fabricated by self-assembly of linear-brush grafted copolymer forming interpolymer complexes by H-bonding in the presence of $\mathrm{pH}$ triggering.

The authors wish to acknowledge the University of Melbourne (Early Career Researcher Grant 2012) for financial support and valuable advices and suggestions from Dr. Adrain Sulistio. 


\section{Notes and references}

1 J. Panyam, V. Labhasetwar, Adv. Drug Deliv. Rev., 2004, 55, 329; M. E. Davis, Z. Chen, D. M. Shin, Nat. Rev. Drug Discovery, 2008, 7, 771.

2 W. Meier, Chem. Soc. Rev. 2000, 29, 295; C. J. Hawker, K. L. Wooley, Science 2005, 309, 1200 ; D. M. Vriezema, A. M. Comellas, J. W. Elemans, J. M. Cornelissen, A. E. Rowan, R. J. M. Nolte, Chem. Rev. 2005, 105, 1445; J. Du, R. K. O'Reilly, Soft Matter, 2009, 5, 3544.

3 D. E. Discher, A. Eisenberg, Science, 2002, 297, 967; L. Zhang, A. Eisenberg, Science, 1995, 268, 1728 .

4 J. del Barrio, L. Oriol, C. Sanchez, J. L. Serrano, P. Keller, M.-H. Li, J. Am. Chem. Soc., 2010, 132, 3762; W. Tao, Y. Liu, B. Jiang, S. Yu, W. Huang, Y. Zhou, D. Yan, J. Am. Chem. Soc., 2012, 134, 762; J. Xu, L. Tao,C. Boyer, A. B. Lowe, T. P. Davis, Macromolecules 2011, 44, 299.

5 D. Le, V. Montembault, J.-C. Soutif, M. Rutnakornpituk, L. Fontaine, Macromolecule, 2010, $43,5611$.

6 M. E. Fox, F. C. Szoka, J. M. J. Frechet, Acc. Chem. Res., 2009, 42, 1141; S. M. Grayson, W. T. Godbey, J. Drug Targeting, 2008, 16, 329.

7 Y. Xia, B. Olsen, J. Kornfield, R. H. Grubbs, J. Am. Chem. Soc., 2009, 131, 18525; J. Johnson, Y. Lu, A. Burts, Y. Lim, M. Finn, J. Koberstein, N. Turro, D. Tirrell, R. H. Grubbs, J. Am. Chem. Soc., 2011, 133, 559.

8 K. L. Smith, A. E. Winslow, D. E. Petersen, Ind. Eng. Chem. 1959, 51, 1361; H. Dou, M. Jiang, H. Peng, D. Chen, Y. Hong, Angew. Chem. Int. Ed. 2003, 42, 1516.

9 A. Wolfberger, B. Rupp, W. Kern, T. Griesser, C. Slugovc, Macromol. Rapid Commum., 2011, 32, 518.

10 L. A. Connal, C. R. Kinnane, A. N. Zelikin, F. Caruso, Chem. Mater 2009, 21, 576; M. Uygun, M. A. Tasdelen, Y. Yagci, Macromol. Chem. Phys., 2010, 211, 103; M. J. Kade, D. J. Burke, C. J. Hawker, J. Polym. Sci. A: Polym. Chem., 2010, 48, 743.

11 Y. Shen, E. Jin, et al. J. Am. Chem. Soc.,2010, 132, 4259; H. Tang, C. J. Murphy, et al. Nanomedicine (London), 2010, 5, 855.

12 F. M. Veronese, G. Pasut, Drug Discovery Today, 2005, 10, 1451.

13 J. H. van Zanten, H. G. Monbouquette, J. Colloid Interface Sci., 1994, 165, 512; J. Pencer, F. R. Hallet, Langmuir, 2003, 19, 7488.

14 G. Bryant, S. Martin, A. Budi, W. van Megen, Langmuir, 2003, 19, 616; H. J. Schöpe, O. Marnette, W. van Megen, G. Bryant, Langmuir, 2007, 23, 11534; A. Sulistio, A. Blencowe, J. Wang, G. Bryant, G. G. Qiao, Macromol. Biosci. 2012, DOI: 10.1002/mabi.201200048.

15 V. T. Huynh, G. Chen, P. de Souza, M. H. Stenzel, Biomacromolecules, 2011, 12, 1738; V. T. Huynh, J. Y. Quek, P. de Souza, M. H. Stenzel, Biomacromolecules, 2012, 13, 1010.

16 R. Tong, J. Cheng, Angew. Chem., Int. Ed., 2008, 47, 4830.

17 A. K. Patri, J. F. Kukowska-Latallo, J. R. Baker, Adv. Drug Deliv. Rev., 2005, 57, 2203; J. Siepmann, A. Gopferich, Adv. Drug Del. Rev., 2001, 48, 229. 


\title{
Novel Drug Carriers: From Grafted Copolymers to Cross-linked Vesicles
}

\author{
Jiangtao Xu, ${ }^{a}$ Qiang Fu, ${ }^{a}$ Jing M. Ren, ${ }^{a}$ Gary Bryant, ${ }^{b}$ Greg G. Qiao ${ }^{a}$ * \\ ${ }^{a}$ Department of Chemical and Biomolecular Engineering, The University of Melbourne, Parkville, \\ Victoria 3010, Australia \\ ${ }^{b}$ School of Applied Sciences, RMIT University, Melbourne, Victoria 3000, Australia \\ *Corresponding author. E-mail: gregghq@unimelb.edu.au
}

\section{Experimental Section}

Materials: poly(ethylene glycol) monoether (Mn $2000 \mathrm{Da}), N$-propargylamine (98\%), copper(I) bromide $(\mathrm{CuBr}, 98 \%), N, N, N$ ', $N$ ', $N$ ',-pentamethyldiethylenetriamine (PMDETA, 99\%), Grubbs catalyst ( $2^{\text {nd }}$ Generation) $\left(\mathrm{H}_{2} \mathrm{IMes}\right)\left(\mathrm{PCy}_{3}\right)(\mathrm{Cl})_{2} \mathrm{RuCHPh}$, cis-dichlorodiaminoplatinum (II) (CDDP, 99.9\%), pentaerythritol tetrakis(3-mercaptopropionate) (PETMP, >95\%), 2,2-dimethoxy-2-phenyl acetophenone (DMPA, 99\%) and anhydrous pyridine (99.8\%) were all purchased from Aldrich and used as received. $N, N$-dimethylformamide $(99.8 \%$, Merck), $n$-hexane (AR, Chem-Supply), diethyl ether (AR, Chem-Supply), sodium azide $\left(\mathrm{NaN}_{3}, 99 \%\right.$, Chem-Supply), 1,8,9-anthrancenetriol (DIT, puriss, Fluka) and trans-2-[3-(4-tert.-butylphenyl)-2-methyl-2-propenylidene]-malononitrile (DCTB, puriss, Fluka) were also used as received. Exo-7-oxabicyclo[2.2.1] hept-5-ene-2,3-dicarboxylic anhydride (oxanorbornenyl anhydride, ONBAn) ${ }^{1}$, azido-terminated poly(ethylene glycol) monomethyl ether with molecular weight 2000 Da $\left(\mathrm{PEG} 2 \mathrm{~K}-\mathrm{N}_{3}\right),{ }^{2,3}$ and pyridine modified Grubbs Catalyst (2 ${ }^{\text {nd }}$ Generation) $\left(\mathrm{H}_{2} \mathrm{IMes}\right)(\mathrm{pyr})_{2}(\mathrm{Cl})_{2} \mathrm{RuCHPh}^{4}$ were synthesized according to literature procedures.

Instrumentation. Gel permeation chromatography (GPC) (THF as eluent) was performed on a Shimadzu liquid chromatography system fitted with a Wyatt DAWN EOS multi-angle laser light scattering (MALLS) detector $(690 \mathrm{~nm}, 30 \mathrm{~mW})$ and a Wyatt OPTILAB DSP interferometric refractometer $(690 \mathrm{~nm})$, using three Phenomenex Phenogel columns (500, 104, and $106 \AA$ porosity; 5 $\mu \mathrm{m}$ bead size) operated at $1 \mathrm{~mL} / \mathrm{min}$ with column temperature set at $40{ }^{\circ} \mathrm{C}$. Astra software (Wyatt Technology Corp.) was used to process the data to determine the molecular weights based on the assumption of $100 \%$ mass recovery of the polymer where the $\mathrm{dn} / \mathrm{dc}$ value was unknown.

${ }^{1} \mathrm{H}$ NMR spectroscopic analysis was performed on a Varian Unity Plus $400 \mathrm{MHz}$ spectrometer using the deuterated solvent as reference.

Hydrodynamic diameters $\left(D_{\mathrm{h}}\right)$ and size distributions of the nanoparticles in aqueous solutions were determined by dynamic light scattering (DLS). DLS measurements were performed using a Malvern high performance particle sizer (HPPS) with a $3.0 \mathrm{~mW}$ He-Ne laser operated at $633 \mathrm{~nm}$ at an angle of $173^{\circ}$ (back scattering) and a constant temperature of $25 \pm 0.1^{\circ} \mathrm{C}$.

A HeNe laser of wavelength $632.8 \mathrm{~nm}$ illuminates the sample, and an avalanche photodiode (APD), located on a goniometer, measures the scattered intensity at a specific scattering angle $\theta$. The accessible angular range is $15^{\circ}-150^{\circ}$, corresponding to a $q$ range of $\sim 3.8-28 \mu \mathrm{m}-1$, encompassing the peak in the structure factor at $q \sim 19 \mu \mathrm{m}-1$. 
Static light scattering (SLS) measurements were performed using a commercially available laser light scattering spectrometer (ALV-DLS/SLS-5022F) equipped with an ALV 6010 multi-tau correlator and Avalanche Photodiode Detectors. The laser source was a He-Ne laser with a power output of $22 \mathrm{~mW}$ operating at a wavelength of $632.8 \mathrm{~nm}$. Samples were prepared in millipore water, filtered with $0.2 \mu \mathrm{m}$ filters, at concentrations from $0.5 \sim 2 \mathrm{mg} / \mathrm{mL}$. Samples were transferred to cylindrical glass scattering cells, and placed in an index matching fluid (ethanol) in a temperature control vat at $25{ }^{\circ} \mathrm{C}$. Light scattered from the sample was detected at 28 angles from $15^{\circ}$ to $150^{\circ}$. The data acquisition was carried out using the ALV-Correlator Control Software, and the accumulation times at each angle were $300 \mathrm{~s}$ to $600 \mathrm{~s}$, depending on concentration.

Matrix-assisted laser desorption/ionization Time of Flight (MALDI-ToF) mass spectroscopy was performed on a Bruker Autoflex III Mass Spectrometer operating in positive linear mode; the analyte, matrix (DCTB) and cationisation agent (NaI) were dissolved in THF at concentrations of 10, 10, and 1 $\mathrm{mg} / \mathrm{mL}$, respectively, and then mixed in a ratio of $10: 1: 1$. Then $0.3 \mu \mathrm{L}$ of this solution was spotted onto a ground steel target plate and the solvent was allowed to evaporate prior to analysis. FlexAnalysis (Bruker) was used to analyze the data.

UV-vis spectrometry was performed on a Shimadzu UV-2101PC spectrometer using quartz cuvettes with a $1 \mathrm{~cm}$ path length.

Transmission electron microscopy (TEM) samples were prepared by directly depositing a droplet of sample solution on copper grid coated by Formvar/Carbon film and draining excess solution by using filter paper after $60 \mathrm{~s}$. To negatively stain the sample, a droplet of $2 \%(\mathrm{w} / \mathrm{v})$ uranyl acetate solution was placed on the copper grid for $30 \mathrm{~s}$ before being drained with filter paper. The grid was then dried in the air for another $20 \mathrm{~min}$. The images were taken using a FEI Tecnai TF20 transmission electron microscope operated at $100 \mathrm{kV}$. Images were acquired digitally with a Gatan US1000 2k $\times 2 \mathrm{k}$ CCD Camera.

Cryo-transmission electron microscopy (Cryo-TEM) samples were prepared and observed as described by Eisenberg. ${ }^{5}$ Frozen hydrated grids of polymer samples were observed on a FEI Tecnai F30 microscope operating at 200kV. Samples were applied to glow-discharged Quantifoil grids (Quantifoil Micro Tools $\mathrm{GmbH}$ ), blotted and frozen in liquid ethane slush and stored in liquid nitrogen until loaded onto a cryogenic sample holder (Gatan 626). Images recorded on a Gatan Ultrascan 4k $\times 4 \mathrm{k}$ Digital (CCD) Camera System under low dose conditions $\left(\sim 10 \mathrm{e}^{-} \AA^{-2}\right)$ at a nominal magnification of 50,000×.

Atomic Force Microscopy (AFM) sample was prepared by depositing a droplet of sample solution on silicon wafer which was treated by Piranha solution. After drying in the air, it was subjected directly for measurement. The images were recorded in air with a JPK microscope operating in dry Tapping mode. The probes were commercially available silicon tips (MicroMasch) with a spring constant of $42 \mathrm{~N} / \mathrm{m}$, a resonance frequency of $285 \mathrm{kHz}$ and a typical radius of curvature in the $10 \sim 12 \mathrm{~nm}$ range. Silicon wafer freshly treated by Piranha solution was used as sample substrate materials.

Thermogravimetric analysis (TGA) was performed on a PerkinElmer Pyris-1 thermogravimetric analyzer, and the samples were heated from 70 to $700{ }^{\circ} \mathrm{C}$ at a heating rate of $10{ }^{\circ} \mathrm{C} / \mathrm{min}$ under a atmosphere flow $(20 \mathrm{~mL} / \mathrm{min})$.

Synthesis of $\omega$-oxanorbornenyl alkyne (ONB-alkyne), 1. Precursor ONB-alkyne was prepared from ONBAn as reported in the literature. ${ }^{6}{ }^{1} \mathrm{H}$ NMR $\left(400 \mathrm{MHz}, \mathrm{CDCl}_{3}\right): \delta$ (ppm) $6.55(\mathrm{~s}, 2 \mathrm{H}$, $\mathrm{CHCH}=C \mathbf{H C H}), 5.31(\mathrm{~s}, 2 \mathrm{H}, \mathrm{OCHCH}=\mathrm{CHCHO}), 4.24\left(\mathrm{~d}, 2 \mathrm{H}, \mathrm{NCH}_{2} \mathrm{CCH}\right), 2.90(\mathrm{~s}, 2 \mathrm{H}, C \mathbf{H C O N})$, $2.19\left(\mathrm{~s}, 1 \mathrm{H}, \mathrm{NCH}_{2} \mathrm{CCH}\right) .{ }^{13} \mathrm{C} \mathrm{NMR}\left(100 \mathrm{MHz}, \mathrm{CDCl}_{3}\right): \delta(\mathrm{ppm})$ 174.3, 137.1, 81.1, 75.2, 70.6, 46.9, 27.1. 
Synthesis of $\omega$-oxanorbornenyl poly(ethylene oxide) $\left(M_{\mathrm{n}}=2000\right)$ macromonomer (ONBPEG2K, 2) via "click" coupling reaction between ONB-alkyne, 1 and PEG2K-N . The general procedure was followed as reported in the literature. ${ }^{3,6}$ The ${ }^{1} \mathrm{H}$ NMR and MALDI-TOF mass characterization of the final product was utilized to confirm the integrity of polymerizable oxanorbornene functionality.

Linear-brush type diblock copolymers of poly(ONBAn)-b-poly(ONB-PEG2K), 3, by ringopening metathesis polymerization (ROMP). In a typical experiment, $8 \mathrm{~mL}$ of distilled THF was degassed by three freeze-pump-thaw cycles. First monomer ONBAn $(0.12 \mathrm{~g})$, second monomer ONBPEG2K (0.162 g) and pyridine modified $2^{\text {nd }}$ generation Grubbs' catalyst $(21 \mathrm{mg})$ were placed in three reaction vessels and evacuated by argon for $5 \mathrm{~min} .2 \mathrm{~mL}$ of THF was added into each monomer flask and $4 \mathrm{~mL}$ into catalyst. After a few minutes, the catalyst solution was added into monomer solution under vigorously stirring. After $5 \mathrm{~min}$, second monomer solution was injected rapidly into the reaction mixture. The reaction mixture was stirred for further 3 hours. The polymerization was terminated by the addition of a few droplets of ethyl vinyl ether. The polymer was then precipitated from diethyl ether twice to yield a grey solid powder. Yield $=100 \%$.

The first monomer ONBAn was easily polymerized to a nearly quantitative yield in 5 min, which was confirmed by the total disappearance of vinyl proton signal at $\delta 6.51 \mathrm{ppm}$ attributed to the oxanorbornene monomer in ${ }^{1} \mathrm{H}$ NMR spectrum (data not shown). The second monomer was added quickly into the reaction solution right after $5 \mathrm{~min}$ and then polymerized for $3 \mathrm{hrs}$. The conversion was confirmed by ${ }^{1} \mathrm{H}$ NMR as well to make sure it was nearly $100 \%$. After termination and purification, it gave light grey powder, 3: $M_{\mathrm{n}}(\mathrm{GPC})=14,500, M_{\mathrm{w}} / M_{\mathrm{n}}=1.14$ for $\mathrm{P}(\mathrm{ONBAn})_{25}-b-\mathrm{P}(\mathrm{ONB}-\mathrm{PEG} 2 \mathrm{~K})_{5}($ the number in the subscript is the repeating units of monomers) and $M_{\mathrm{n}}(\mathrm{GPC})=19,400 \mathrm{~K}, M_{\mathrm{w}} / M_{\mathrm{n}}=1.16$ for $\mathrm{P}(\mathrm{ONBAn})_{50}-b-\mathrm{P}(\mathrm{ONB}-\mathrm{PEG} 2 \mathrm{~K})_{5}$.

Hydrolysis of diblock copolymers, 3 to yield poly(ONBA)-b-poly(ONB-PEG2K), 4. The block copolymer $(0.31 \mathrm{~g})$ was added into $15 \mathrm{~mL} 0.1 \mathrm{M} \mathrm{NaOH}$ solution. This solution was stirred for 1 hour until it turned to be clear. The solution was then dialyzed against distilled water for 2 days to remove $\mathrm{NaOH}$ using Spectra/Por (Spectrum Laboratories Inc.) regenerated cellulose dialysis membrane with a molecular weight cutoff of $2000 \mathrm{Da}$. After freeze-drying, grey viscous product, 4, was obtained for further self-assembly without treatment: $\mathrm{P}(\mathrm{ONB}-\text { diacid })_{25}-b-\mathrm{P}(\mathrm{ONB}-\mathrm{PEG} 2 \mathrm{~K})_{5}$ (denoted as $\left.\mathrm{DP} 25\right)$ and $\mathrm{P}(\mathrm{ONB} \text {-diacid })_{50}-b-\mathrm{P}(\mathrm{ONB}-\mathrm{PEG} 2 \mathrm{~K})_{5}$ (denoted as DP50), respectively.

Preparation and cross-linking of polymer vesicles from poly(ONB-diacid $)_{\mathrm{m}}-b$-poly(ONBPEG2K $)_{\mathrm{n}}$, 4. The diblock copolymer, $4\left(M_{\mathrm{n}}=14,500,30 \mathrm{mg}, 2.07 \times 10^{-6} \mathrm{~mol}\right)$ was dissolved in $10 \mathrm{~mL}$ milli-Q water at a concentration of $3 \mathrm{mg} / \mathrm{mL}$. $\mathrm{pH}$ value of the solution was adjusted to be $\sim 12$ (measured by $\mathrm{pH}$ meter) by adding $2 \mathrm{M} \mathrm{NaOH}$ solution $(\sim 50 \mu \mathrm{L})$. Sample was then filtered through a PTFE filter (pore size $0.45 \mu \mathrm{m}$ ). Subsequently, $2 \mathrm{M} \mathrm{HCl}$ solution was added dropwise into the solution until the $\mathrm{pH}$ value to 4 . The particle size was confirmed by dynamic light scattering (DLS).

A solution of cross-linker PETMP $\left(7 \mathrm{mg}, 1.43 \times 10^{-5} \mathrm{~mol}\right)$ and photo initiator DMPA (1.6 mg, $6.24 \times$ $\left.10^{-6} \mathrm{~mol}\right)$ was prepared in $2 \mathrm{~mL}$ distilled THF. An aliquot of $200 \mu \mathrm{L}$ solution was withdrawn and added slowly into above polymer micellar solution with stirring. The mixture was kept stirring for extra 4 hours under dark and then radiated under $365 \mathrm{~nm}$ UV lamp for overnight. The final solution was dialyzed again milli-Q water for 2 days to remove all impurities including excess THF and some salts using regenerated cellulose dialysis membrane with a molecular weight cutoff of $8000 \mathrm{Da}$. At the meantime, $\mathrm{pH}$ value was increased to 7. Morphological observation of the cross-linked polymer micellar suspension was performed by DLS, SLS, TEM and AFM.

Drug conjugation of cis-platinum to cross-linked polymer vesicles. The conjugation of cisplatinum to the polymer vesicles was followed by modified procedure as reported in the literatures. ${ }^{7,8}$ 
The complex can be obtained either by adding cis-dichlorodiamine-platinum(II) (CDDP), one of popular forms of $c i s$-platinum drugs, directly to the aqueous solution of cross-linked polymer vesicles, or via the reaction with cis-diaminediaqua platinum(II) complex obtained by hydrolysis of CDDP by adding $\mathrm{AgNO}_{3}$. The later has much higher rate of complexation than the former.

CDDP (10 mg) was suspended in $10 \mathrm{~mL}$ distilled water and mixed with silver nitrate $\left(\left[\mathrm{AgNO}_{3}\right] /[\mathrm{CDDP}]=1.955\right)$ to form the aqueous complex. The solution was stirred in the dark at room temperature for $4 \mathrm{~h}$. White precipitate of silver chloride was observed indicative of the proceeding reaction. The mixture was then centrifuged at $4400 \mathrm{rpm}$ for 1 hour to remove the $\mathrm{AgCl}$ precipitates and the supernatant was purified by passing through a $0.22 \mu \mathrm{m}$ filter. Polymers vesicles $(38 \mathrm{mg}$, dissolved in $3 \mathrm{~mL}$ of $\mathrm{NaOH}$ solution $(1 \mathrm{mg} / \mathrm{mL})$ and stirred for half an hour) were added to the above CDDP aqueous solution and left to react in a water bath at $37{ }^{\circ} \mathrm{C}$ for $12 \mathrm{~h}$ with gentle shaking resulting in polymer-platinum conjugates. The resultant conjugates were purified by dialysis against distilled water using regenerated cellulose dialysis membrane with a molecular weight cut-off of 8000 Da, followed by freeze-drying, yielding light brown powder.

The platinum conjugation efficiency to polymer nanoparticles was defined as followed and determined by TGA:

$$
f=\frac{m_{P t, \text { exp }}}{m_{P t, \text { theo }}} \times 100 \%=\frac{W_{P t} / M_{P t}}{W_{\text {di-acid }} / M_{\text {di-acid }}} \times 100 \%
$$

where $m_{P t \text {, exp }}$ : the molar amount of Pt determined by experimental data; $m_{P t, \text { theo }}$ : the theoretical molar amount of $\mathrm{Pt}$ in $100 \%$ conversion (assume that one $\mathrm{Pt}$ molecule forms complex with one di-acid repeating unit); $W_{P t}$ : weight percent of Pt measured by TGA; $M_{P t}$ : molecular weight of Pt; $W_{\text {di-acid }}$ : weight percent of di-acid repeat unit calculated by TGA data; $M_{d i-a c i d}$ : molecular weight of di-acid repeating unit.

The platinum loading content to polymer nanoparticles was defined as:

$$
\text { Loading content }=\frac{\text { amount of loaded CDDP }}{\text { amount of polymer carrier }+ \text { amount of loaded CDDP }} \times 100 \%
$$

Release of platinum drug from polymer-platinum conjugates. The release of the platinum drug from the polymer vesicles can be triggered by the presence of chloride ions, which will lead to ligand exchange of the platinum complex from carboxylato ligand to chloride ligand. The drug is then cleaved from the polymer vesicles as CDDP. This process is favoured in the presence of high amounts of chlorides, but not in chloride free buffers. Buffers such as the chloride containing phosphate buffered saline (PBS) or simple saline $(0.9 \%)$ can force the release of CDDP. The in vitro release of the CDDP from polymer vesicle solution was performed by a dialysis method. The polymer-platinum conjugate (cis-platinum loaded CPV25) at a concentration of $5 \mathrm{mg} / \mathrm{mL}$ was added to dialysis tubing and dialyzed at $37{ }^{\circ} \mathrm{C}$ against $0.9 \%$ saline solution of $\mathrm{pH} 7.4$, which mimics the environment in plasma. At certain time intervals, the release medium was sampled and analysed by means of $o$-phenylenediamine colorimetric assay (o-PDA).

Polymeric platinum conjugates $(10 \mathrm{mg})$ were dissolved in $2 \mathrm{~mL}$ saline solution $0.9 \% \mathrm{NaCl}(\mathrm{pH} 7.4)$ and dialyzed (cellulose tubing with molecular weight cut-off of approximately $8000 \mathrm{Da}$ ) against saline $0.9 \%$ solution $(1 \mathrm{~L})$ at $37{ }^{\circ} \mathrm{C}$. Aliquots of $1 \mathrm{~mL}$ were taken at regular time intervals from the dialysate over $143.5 \mathrm{~h}$. The amount of released $\mathrm{Pt}$ was determined using the $o$-phenylenediamine colorimetric assay (o-PDA) carried out according to a previously published method. ${ }^{8-10}$

Samples with an unknown $\mathrm{Pt}$ content were added to $1 \mathrm{~mL}$ of $o$-PDA solution in $N, N^{\prime}-$ dimethylformamide (DMF) $2 \mathrm{mg} / \mathrm{mL}$ ) and heated for $10 \mathrm{~min}$ at $100{ }^{\circ} \mathrm{C}$. The amount of Pt present in the sample was determined by measuring the absorbance at $703 \mathrm{~nm}$ using CDDP as a standard curve. The 
concentration of Pt released from the conjugate was expressed as a ratio of the amount platinum in the releasing solution and that in the initial sample. The percentage of Pt released was calculated using the equation below.

$$
\% \text { CDDP released }=\frac{V_{\text {total }}(t) \times C+Y}{Z}
$$

where $\mathrm{V}_{\text {total }}(t)$ : remaining volume in the releasing container at time $t, \mathrm{~mL} ; C$ : concentration of platinum determined from $\mathrm{UV}^{-}$-vis measurements, $\mu \mathrm{g} / \mathrm{mL}$; Y: the amount of platinum that has already been collected, $\mu \mathrm{g}$; Z: total amount of platinum at $t=0$ present in the dialysis bag, $\mu \mathrm{g}$. 
Synthesis and Characterization of Diblock Copolymer

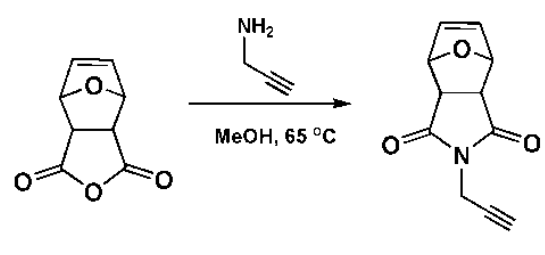

ONBAn

ONB-alkyne, 1

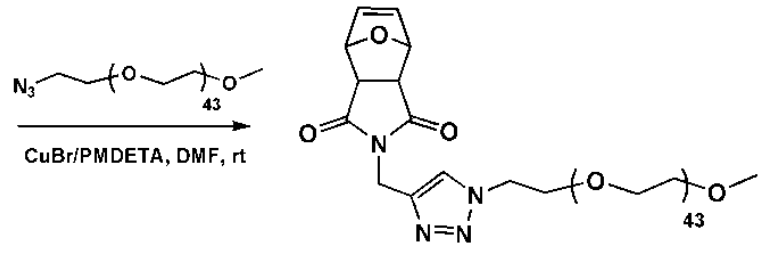

ONB-PEG2K, 2

Scheme S1 Synthesis of $\omega$-oxanorbornenyl poly(ethylene oxide) $\left(M_{\mathrm{n}}=2000\right)$ macromonomer (ONBPEG2K), 2.

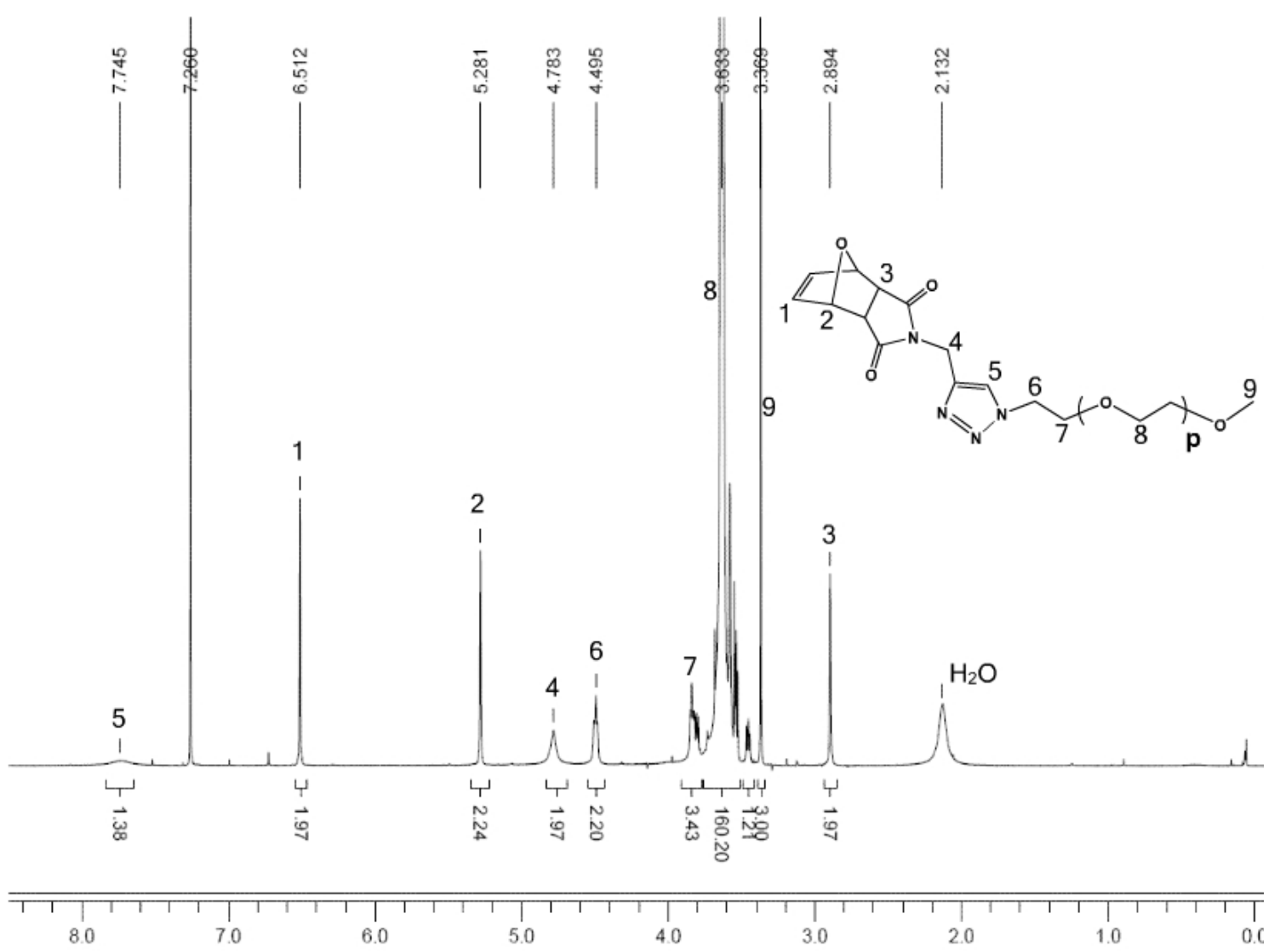

Fig. S1 ${ }^{1}$ H NMR spectrum of macromonomer ONB-PEG2K, 2. 


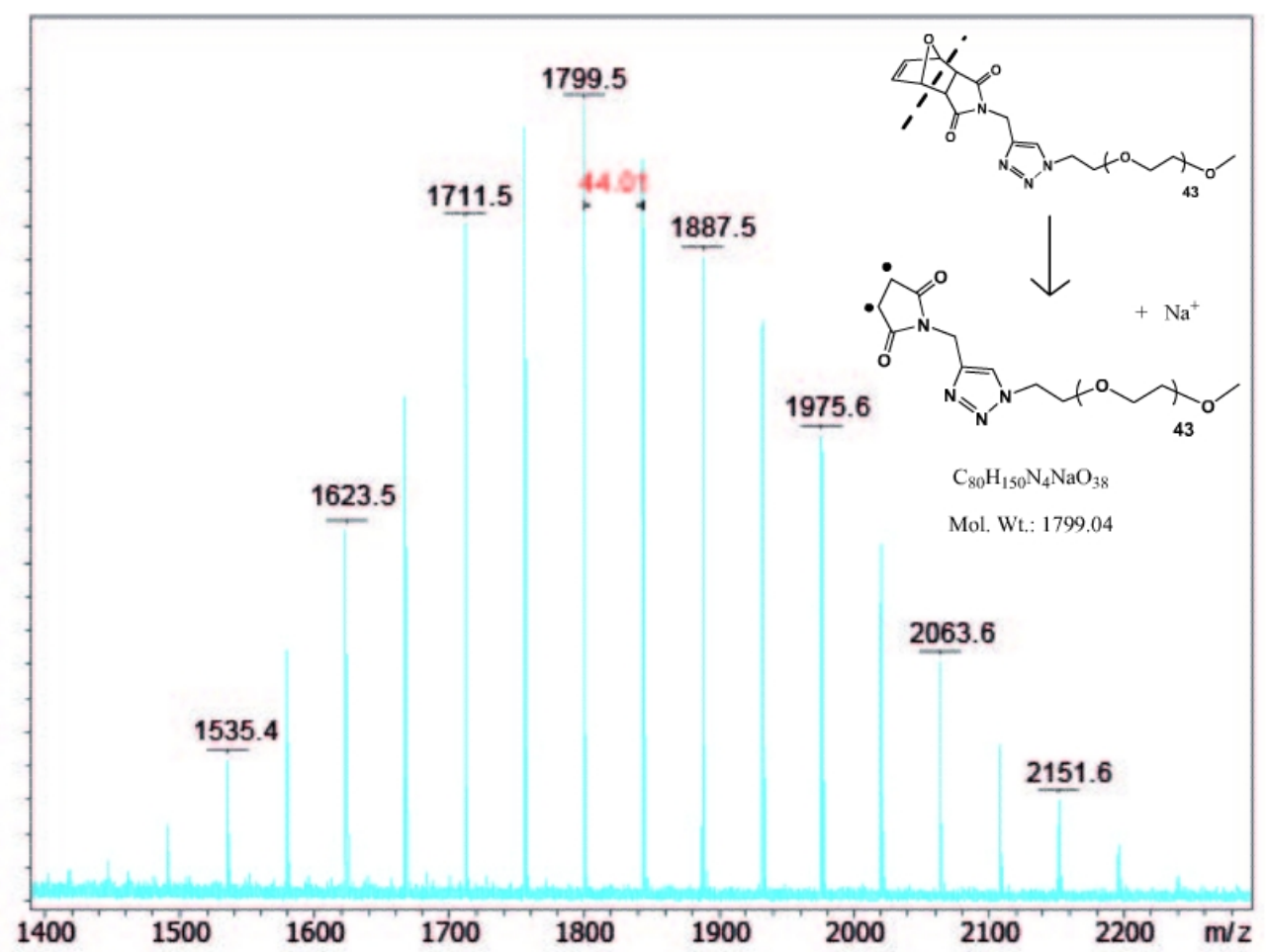

Fig. S2 MALDI-TOF mass spectrum of macromonomer ONB-PEG2K, 2.

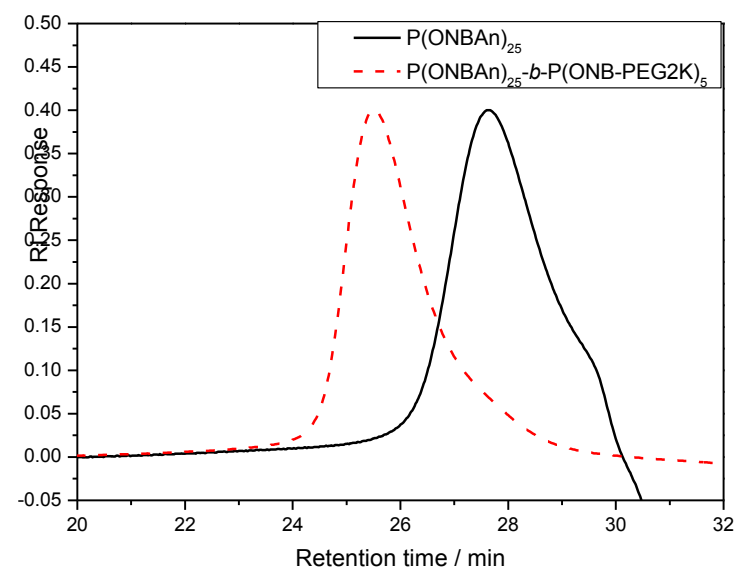

$\mathrm{P}(\mathrm{ONBAn})_{25}-b-\mathrm{P}(\mathrm{ONB}-\mathrm{PEG} 2 \mathrm{~K})_{5}$

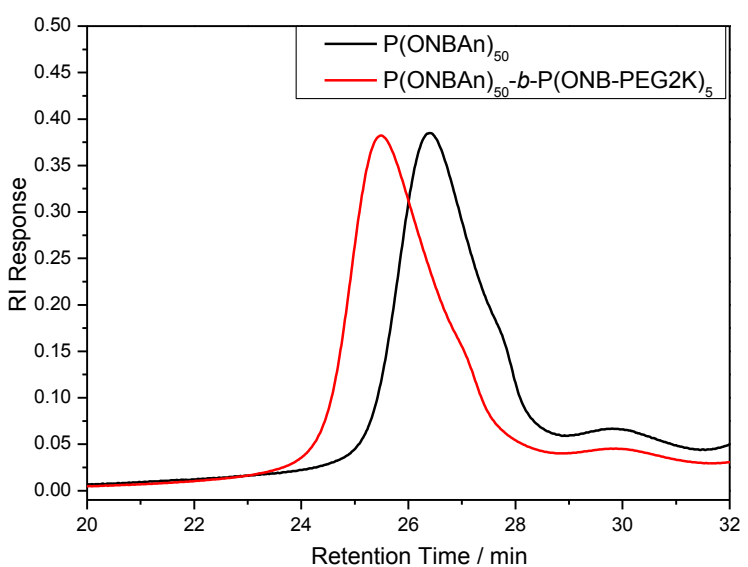

$\mathrm{P}(\mathrm{ONBAn})_{50}-b-\mathrm{P}(\mathrm{ONB}-\mathrm{PEG} 2 \mathrm{~K})_{5}$

Fig. S3 GPC traces of diblock copolymers $\mathrm{P}(\mathrm{ONBAn})_{\mathrm{m}}-b-\mathrm{P}(\mathrm{ONB}-\mathrm{PEG} 2 \mathrm{~K})_{\mathrm{n}}, \mathbf{3}$. 


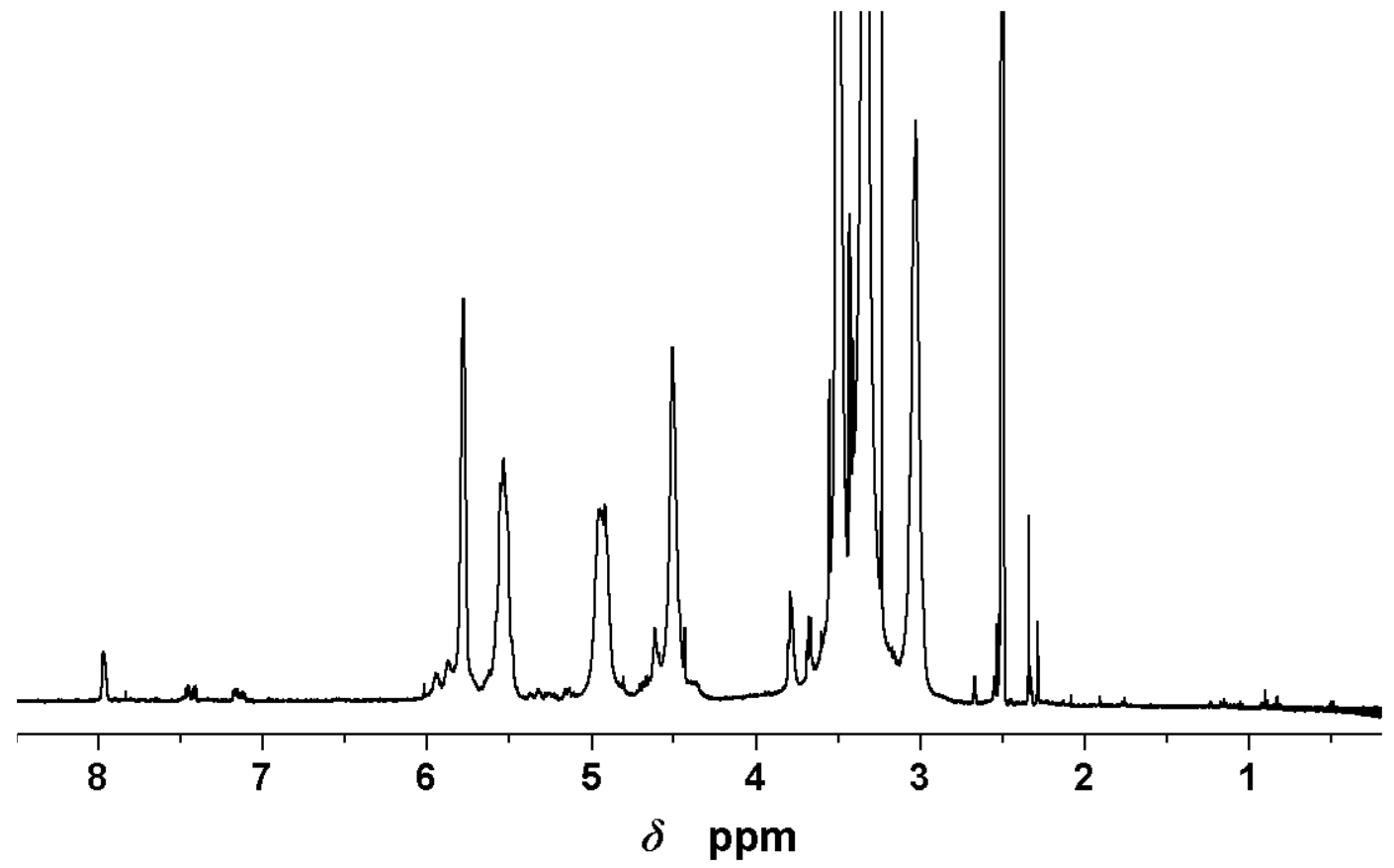

Fig. S4 Typical ${ }^{1} \mathrm{H}$ NMR spectrum of diblock copolymers $\mathrm{P}(\mathrm{ONBAn})_{\mathrm{m}}-b-\mathrm{P}(\mathrm{ONB}-\mathrm{PEG} 2 \mathrm{~K})_{\mathrm{n}}, \mathbf{3}$. 


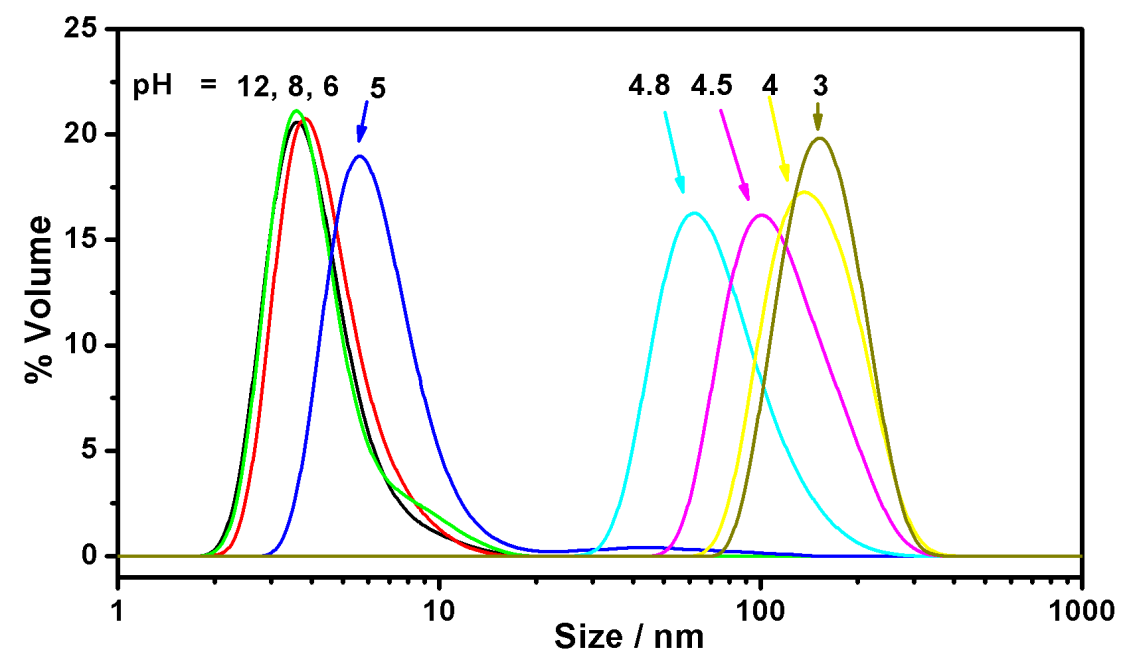

Fig. S5 Hydrodynamic particle size distributions of linear-brush diblock copolymer $\mathrm{P}\left(\mathrm{ONB}\right.$-diacid ${ }_{25}-b$ $\mathrm{P}(\mathrm{ONB}-\mathrm{PEG} 2 \mathrm{~K})_{5}(\mathrm{DP} 25)$ at different $\mathrm{pH}$. The concentration was $3 \mathrm{mg} / \mathrm{mL}$. The $D_{\mathrm{h}}$ values were measured 10 min after the solutions preparation.
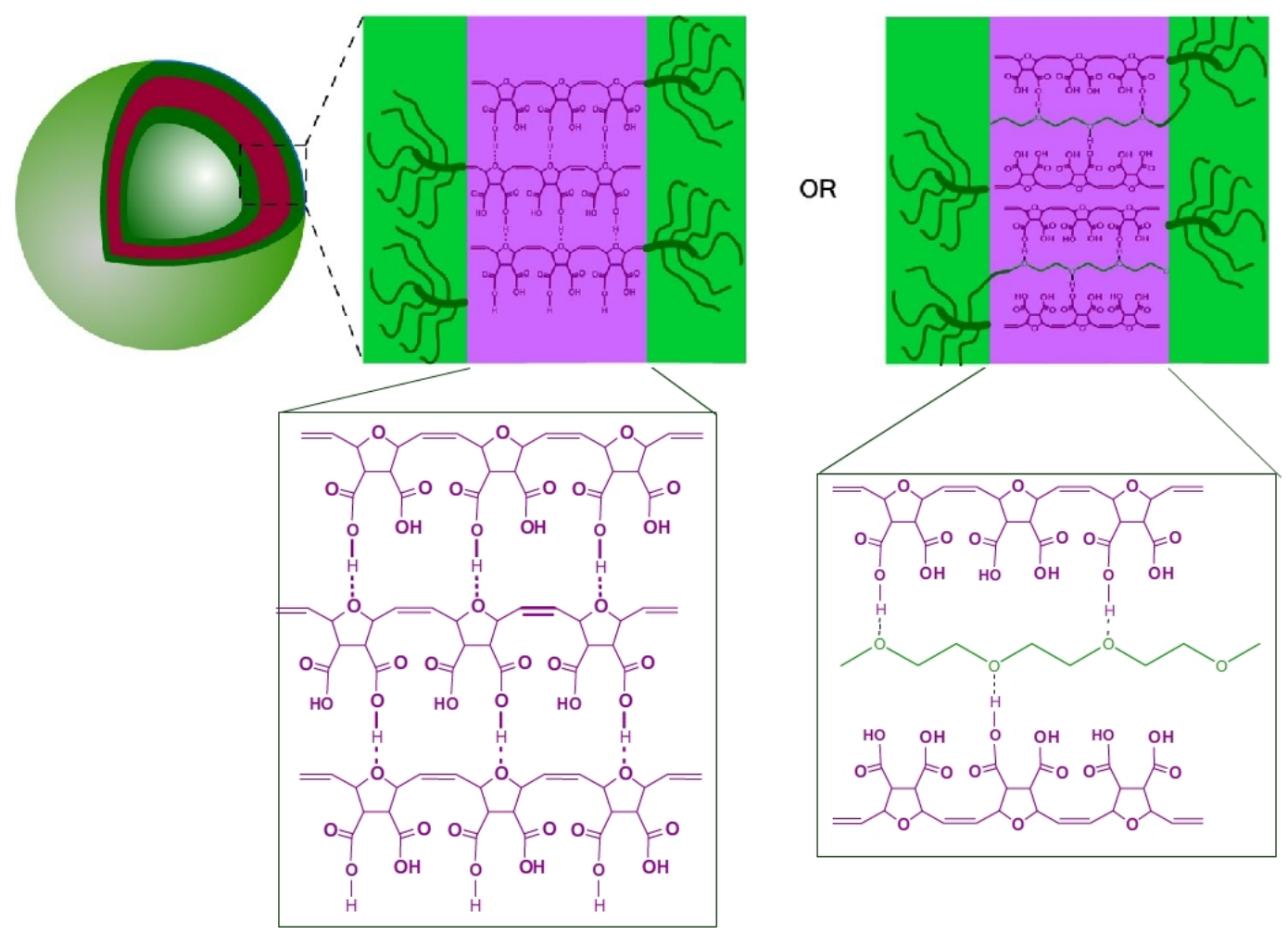

Scheme S2 The proposed chemical structures of interpolymer complexation (IPC) between poly(carboxylic acid) and polyoxanorbornene ether backbone, PEG brush or both for the self-assembly of block copolymer $\mathrm{P}(\mathrm{ONB}-\mathrm{diacid})_{\mathrm{m}}-b-\mathrm{P}(\mathrm{ONB}-\mathrm{PEG} 2 \mathrm{~K})_{\mathrm{n}}, \mathbf{4}$, in acidic solutions. As shown in the scheme, the polymer vesicle structure would not be destroyed at all even if all of the protonated acid functionalities form complex only with PEG brush, because the amounts of ether groups in PEG brush are far more than protonated acid functionalities in the used $\mathrm{pH}$ range. 


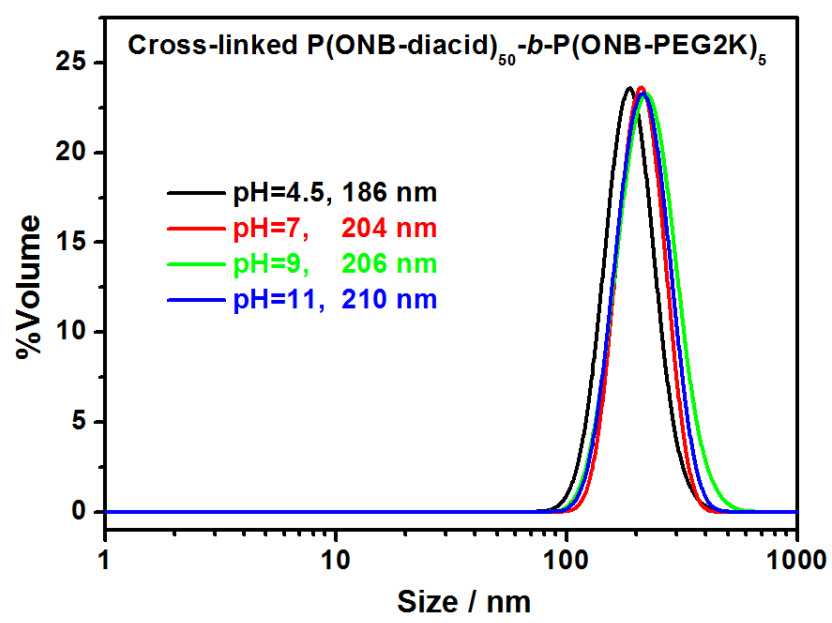

Fig. S6 Particle sizes and size distributions of self-assembled diblock copolymer $\mathrm{P}(\mathrm{ONB} \text {-diacid })_{50}-b-$ $\mathrm{P}(\mathrm{ONB}-\mathrm{PEG} 2 \mathrm{~K})_{5}(\mathrm{DP} 50)$ at different $\mathrm{pH}$ conditions after cross-linking.

\section{SLS Measurements}

For small sized particles ( $\mathrm{qR}<1$, where $\mathrm{q}=$ scattering vector and $\mathrm{R}$ is the aggregate radius), the radius of gyration $R_{\mathrm{g}}$ can be calculated from a Zimm plot or Guinier approximation. When the ratio of $R_{\mathrm{g}} / R_{\mathrm{h}}$ is close to unity it indicates that a hollow particle (vesicle) is present, as opposed to a value of 0.77 , which corresponds to a solid sphere or micelle. ${ }^{112}$ However, in this case the qR values are greater than 1 and $R_{\mathrm{g}}$ cannot be easily measured using this technique.

Instead the intensity as a function of scattering angle of incident light was measured and fitted with mathematical models for both spherical hollow spheres (vesicles) and solid spheres (micelles) in order to confirm whether or not the self-assemblies truly are vesicles, and determine particle sizes and shell thickness. ${ }^{13}$ The scattering factor, $\mathrm{P}(q)$, for hollow spheres with a shell of thickness $t$ can be expressed as follows:

$$
\mathrm{P}(q)=\left(\frac{3}{R_{0}^{3}-R_{i}^{3}}\right)^{2} \times\left[R_{0}^{3} \frac{j_{1}\left(q R_{0}\right)}{q R_{0}}-R_{i}^{3} \frac{j_{1}\left(q R_{i}\right)}{q R_{i}}\right]^{2}
$$

Where $R$ is the average radius, $R_{0}=R+t / 2$ is the outer radius, $R_{\mathrm{i}}=R-t / 2$ is the inner radius and $j_{l}(x)$ is the first-order spherical Bessel function given by:

$$
j_{1}(x)=\frac{\sin x}{x^{2}}-\frac{\cos x}{x}
$$

As a comparison, a solid sphere model (as would be the case for a micelle) is also used:

$$
\mathrm{P}(q)=\frac{4}{3} \pi R^{3} \times \frac{3[\sin (q R)-q R \cos (q R)]}{(q R)^{3}}
$$

In a polydisperse suspension of particles, the total scattering intensity as a function of angle will be given by:

$$
I(q)=\int_{0}^{\infty} R^{6} P(q, R) G(R) d R
$$

where $G(R)$ is the particle size distribution. Both log-normal and Schultz distributions were tried, each characterized by a mean radius, $\mathrm{R}$, and a polydispersity, $\sigma$. The details of the analysis and fitting methods are described in previous publications. ${ }^{14,15}$ 


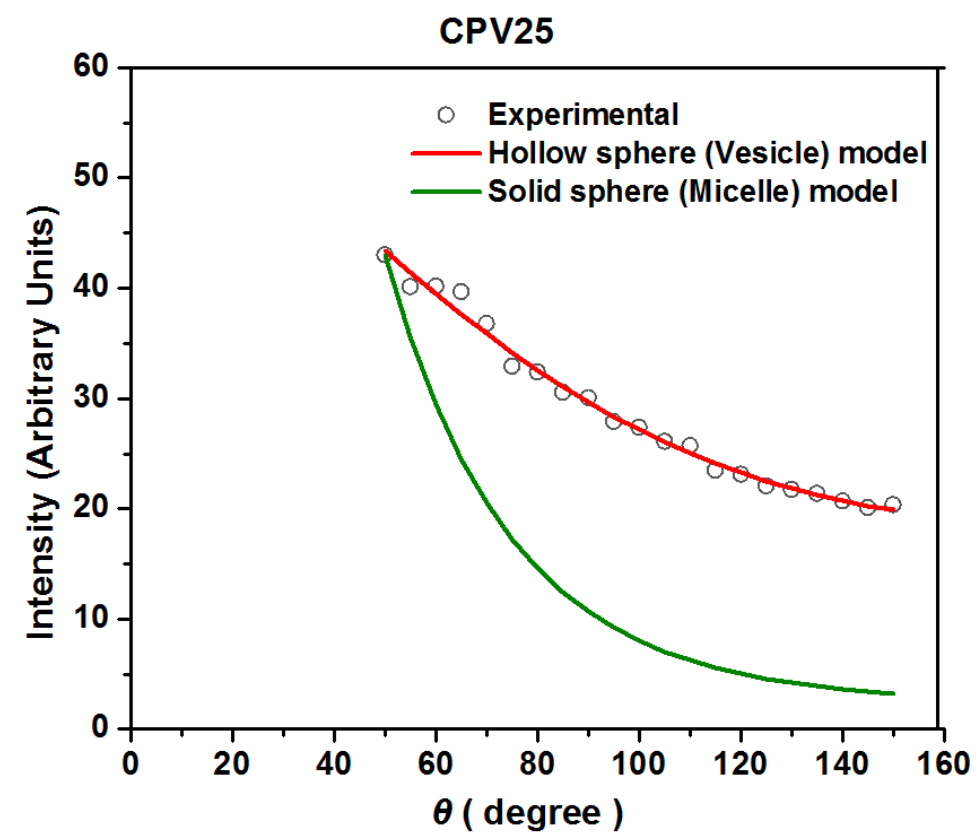

Fig. S7 Scattered intensity correlation as a function of the angle of incident light for the cross-linked polymer vesicle from $\mathrm{P}(\mathrm{ONB}-\mathrm{diacid})_{25}-b-\mathrm{P}(\mathrm{ONB}-\mathrm{PEG} 2 \mathrm{~K})_{5}(\mathrm{CPV} 25)$. The lines correspond to the fits generated using the hollow sphere (vesicle) (red line) and solid sphere (micelle) model (green line). Particle size $D=132 \mathrm{~nm}$; Shell thickness $t=27 \mathrm{~nm}, \log$ Normal distribution with $\sigma=43 \%$. No good fit could be obtained with the solid sphere model: for comparison, the calculated data for a solid sphere with the same parameters is shown (green line).

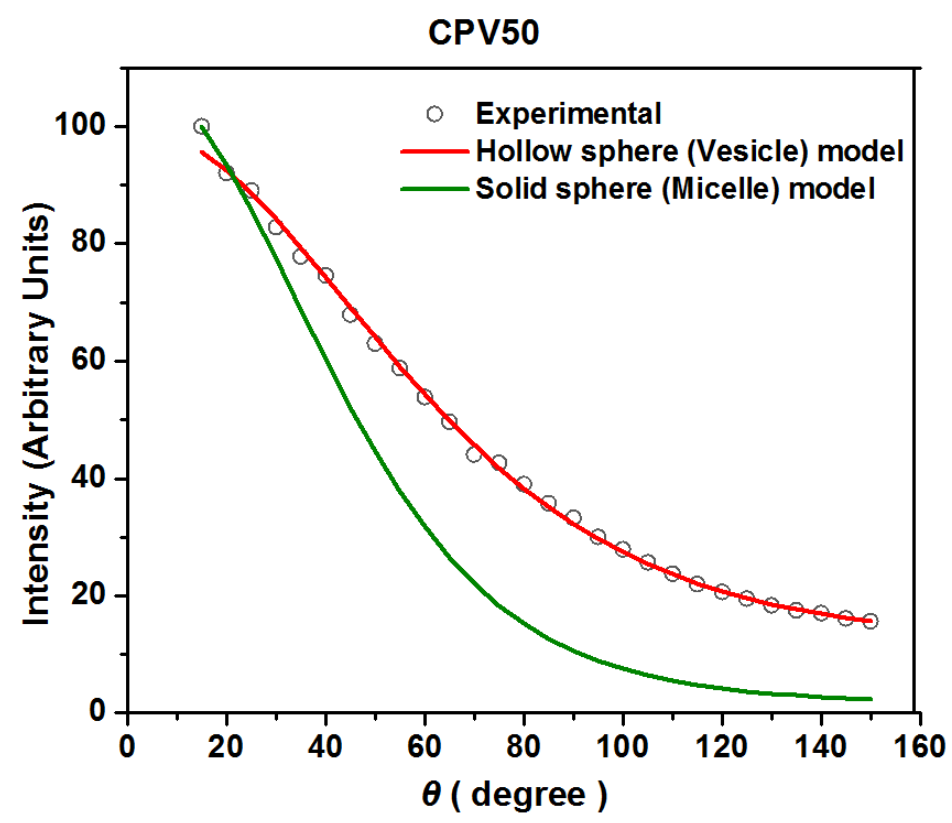

Fig. S8 Scattered intensity correlation as a function of the angle of incident light for the cross-linked polymer vesicle from $\mathrm{P}(\mathrm{ONB}-\mathrm{diacid})_{50}-b-\mathrm{P}(\mathrm{ONB}-\mathrm{PEG} 2 \mathrm{~K})_{5}(\mathrm{CPV} 50)$. The lines correspond to the fits generated using the hollow sphere (vesicle) (red line) and solid sphere (micelle) model (green line). Particle size $D=188 \mathrm{~nm}$; Shell thickness $t=37 \mathrm{~nm}$, Schultz distribution with $\sigma=31 \%$. No good fit could be obtained with the solid sphere model: for comparison, the calculated data for a solid sphere with the same parameters is shown (green line). 
The two different samples were fitted with both log-normal distributions and Schultz distributions, assuming both solid sphere (micelle) and hollow sphere (vesicle) models, and the best fit results are shown in the figures above (Fig. S7 \& S8). The size distributions of the vesicle fits are shown in Fig. S9, which shows that CPV25 has a smaller average size, but a larger polydispersity (distribution width) than CPV50. The large polydispersities are consistent with the results from Cryo-TEM

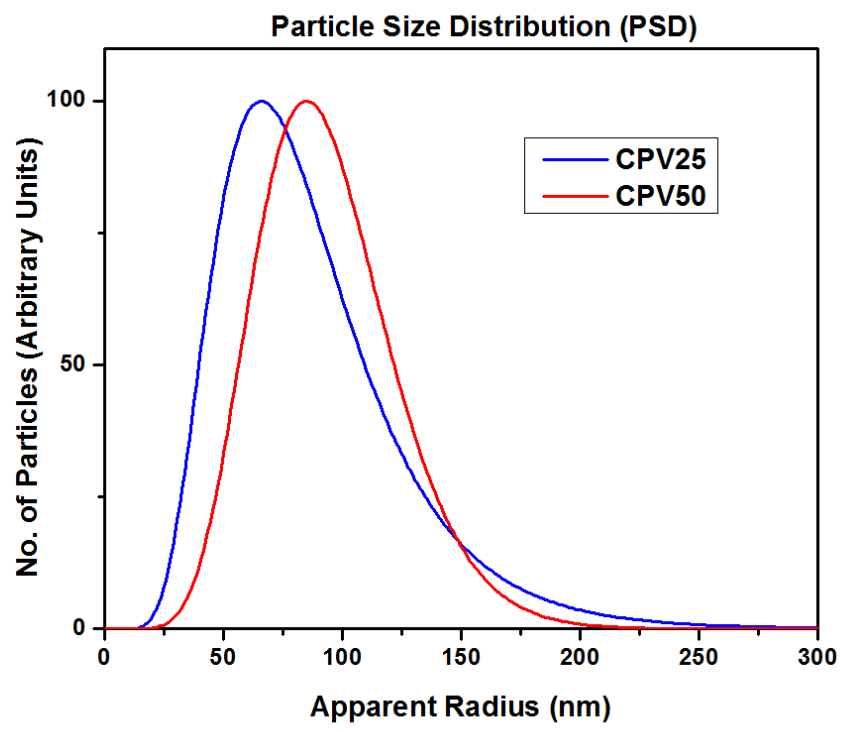

Fig. S9 Particle size distributions for samples of cross-linked polymer vesicles from diblock copolymer $\mathrm{P}(\mathrm{ONB}-\text { diacid })_{25}-b-\mathrm{P}(\mathrm{ONB}-\mathrm{PEG} 2 \mathrm{~K})_{5}$ (CPV25) (blue line) and $\mathrm{P}(\mathrm{ONB}-\text { diacid })_{50}-b-\mathrm{P}(\mathrm{ONB}-\mathrm{PEG} 2 \mathrm{~K})_{5}$ (CPV50) (red line). It is worthy to note that CPV25 has a smaller average size, but a wider particle distribution than CPV50. 
Transmission Electron Microscopy (TEM) and Cryo-TEM Measurements
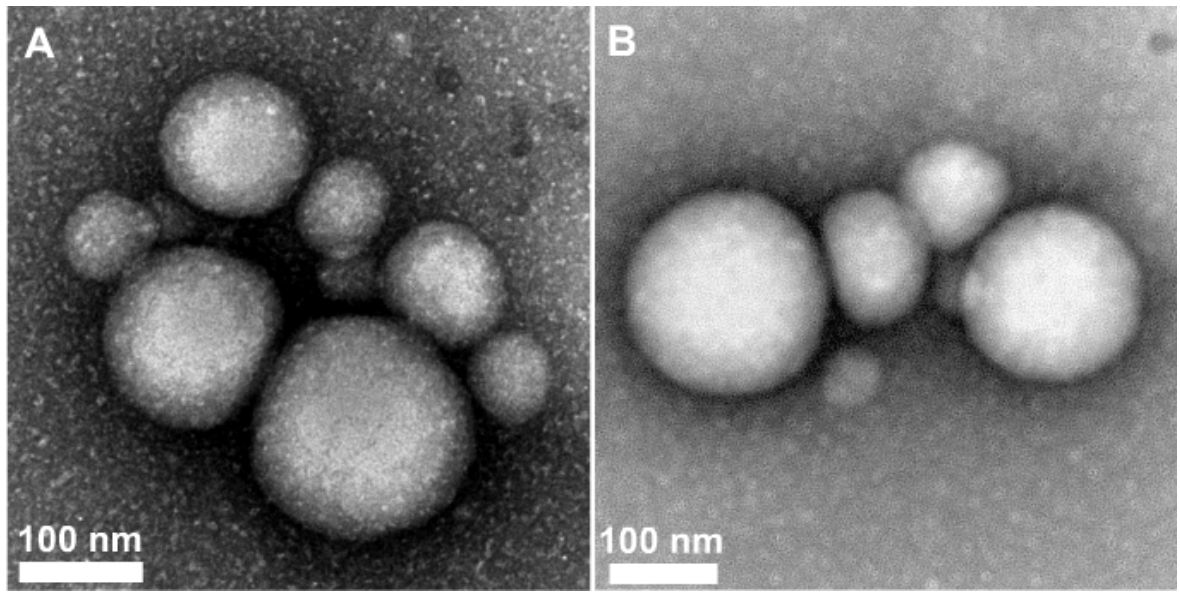

Fig. S10 TEM images with negative staining for the dried sample of cross-linked polymer vesicle from $\mathrm{P}(\mathrm{ONB}-\text { diacid })_{25}-b$-P(ONB-PEG2K $)_{5}(\mathrm{CPV} 25)$.
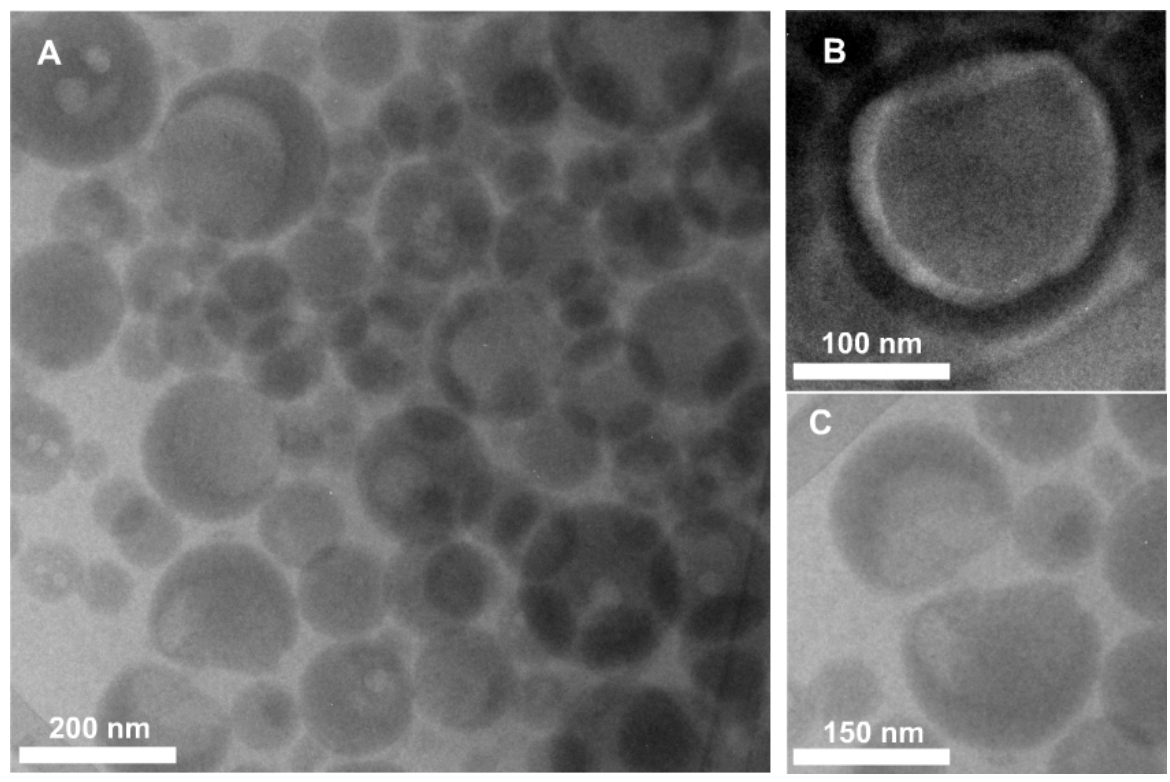

Fig. S11 Cryo-TEM images for the sample of cross-linked polymer vesicle from $\mathrm{P}(\mathrm{ONB} \text {-diacid })_{25}-b$ $\mathrm{P}(\mathrm{ONB}-\mathrm{PEG} 2 \mathrm{~K})_{5}(\mathrm{CPV} 25)$ with positive staining after $c i s$-platinum loading. 


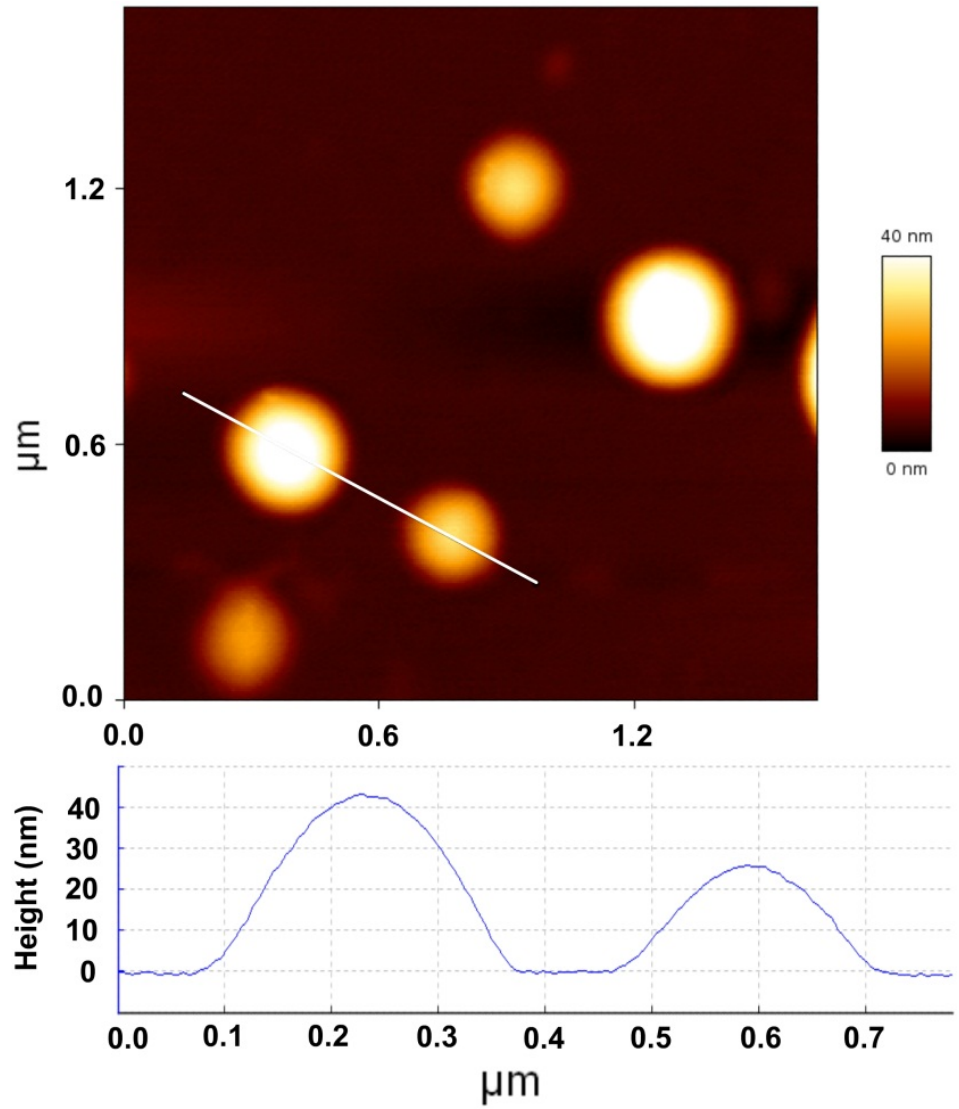

Fig. S12 Atomic Force Microscopy (AFM) image for the sample of cross-linked polymer vesicle from $\mathrm{P}(\mathrm{ONB}-\mathrm{diacid})_{25}-b-\mathrm{P}(\mathrm{ONB}-\mathrm{PEG} 2 \mathrm{~K})_{5}$ (CPV25). The different thickness of two particles (44 $\mathrm{nm}$ and $25 \mathrm{~nm}$ ) as indicated was originated from two distinguished particle shapes: fully enclosed (doubled shell thickness) and partially enclosed vesicles (singled shell thickness). 
Cis-Platinum Drug Loading and Drug Release

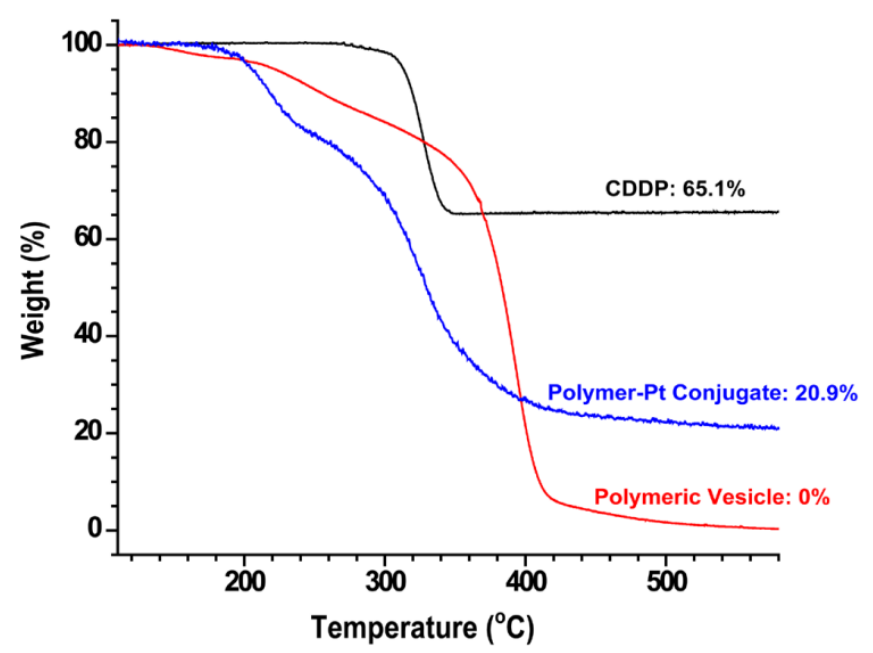

Fig. S13 TGA traces for CDDP (black), cross-linked polymer vesicle from $\mathrm{P}(\mathrm{ONB}-\mathrm{diacid})_{25}-b$ - $\mathrm{P}(\mathrm{ONB}-$ PEG2K $)_{5}(\mathrm{CPV} 25$, red) and polymer-platinum conjugate (blue, drug loaded polymer vesicles).

Calculation of drug conjugation efficiency based on TGA data:

$$
\begin{aligned}
f & =\frac{m_{P t, \text { exp }}}{m_{P t, \text { theo }}} \times 100 \%=\frac{W_{P t} /_{P t}}{W_{\text {di-acid }} / M_{\text {di-acid }}} \times 100 \% \\
& =\frac{20.9 \% / 195}{\left[\left(79.1 \%-\frac{20.9 \% \times 34.9}{65.1}\right) \times \frac{4100}{4100+10000}\right] / 164} \times 100 \% \\
& =88.4 \%
\end{aligned}
$$

Calculation of drug loading content based on conjugation efficiency:

$$
\begin{aligned}
\text { Loading content } & =\frac{\text { amount of loaded CDDP }}{\text { amount of polymer carrier }+ \text { amount of loaded CDDP }} \times 100 \% \\
& =\frac{10 \mathrm{mg} \times 88.4 \%}{38 \mathrm{mg}+10 \mathrm{mg} \times 88.4 \%} \times 100 \%=18.9 \%
\end{aligned}
$$




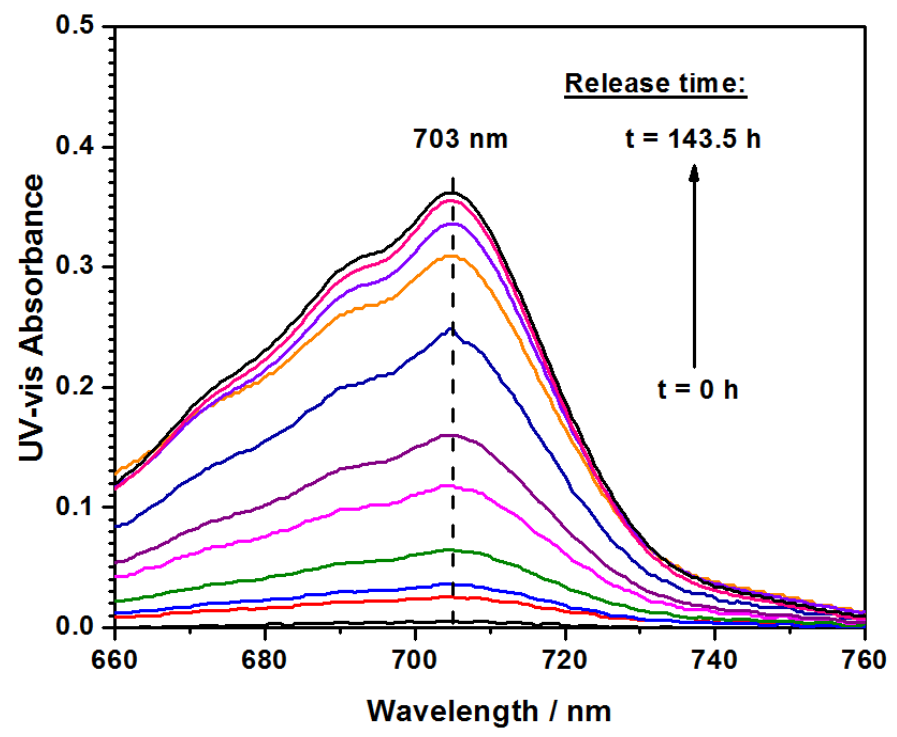

Fig. S14 UV-vis spectra for the samples withdrawn at different time intervals during drug release study.

\section{References}

1. , R. B. WoodwardH. Baer, J. Am. Chem. Soc. 1948, 70, 1161-1166.

2. H. Gao, K. Matyjaszewski, J. Am. Chem. Soc. 2007, 129, 6633-6639.

3. J.-M. Ren, J. Wiltshire, A. Blencowe, G. G. Qiao, Macromolecule 2011, 44, 3189-3202.

4. J. A. Love, J. P. Morgan, T. M. Trnka, R. H. Grubbs, Angew. Chem. Int. Ed. 2002, 41, 4035-4037.

5. S. Yu, T. Azzam, I. Rouiller, A. Eisenberg, J. Am. Chem. Soc. 2009, 131, 10557-10566.

6. D. Le, V. Montembault, J.-C. Soutif, M. Rutnakornpituk, L. Fontaine, Macromolecule 2010, 43, 5611-5617.

7. H. Ye, L. Jin, R. Hu, Z. Yi, J. Li, Y. Wu, X. Xi, Z. Wu, Biomaterials 2006, 27, 5958-5965.

8. V. T. Huynh, G. Chen, P. de Souza, M. H. Stenzel, Biomacromolecules 2011, 12, 1738-1751.

9. E. Gianasi, M. Wasil, E. G. Evagorou, A. Keddle, G. Wilson, R. Duncan, Eur. J. Cancer 1999, 35 , 994-1002.

10. B. Schechter, A. Neumann, M. Wilchek, R. Arnon, J. Controlled Release 1989, 10, 75-87.

11. H. Huang, B. Chung, J. Jung, H.-W. Park, T. Chang, Angew. Chem. Int. Ed 2009, 121, 4594-4597.

12. W. Burchard, Adv. Polym. Sci. 1983, 48, 1.-124

13. J. Pencer, F. R. Hallet, Langmuir, 2003, 19, 7488-7497.

14. G. Bryant, S. Martin, A. Budi, W. van Megen, Langmuir, 2003, 19, 616-621.

15. H. J. Schöpe, O. Marnette, W. van Megen, G. Bryant, Langmuir, 2007, 23, 11534-11539. 